\title{
Multi-phase generators viability for offshore wind farms with HVDC transmission.
}

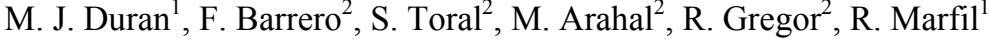 \\ ${ }^{1}$ Electrical Engineering Department \\ School of Engineering, University of Málaga \\ Plaza del Ejido S/N, 29120, Málaga (Spain) \\ Tlf. 952 132707, email: mjduran@uma.es \\ ${ }^{2}$ Electronic \& Automatic Engineering Department \\ School of Engineering, University of Seville \\ Camino de los descubrimientos S/N, 41092, Sevilla (Spain) \\ Tlf.954 481281, email: fbarrero@esi.us.es
}

\begin{abstract}
The interest in offshore wind farms has experienced a significant growth in recent years. Technical knowledge allow the design of wind farms at higher distances, making the high voltage dc (HVDC) transmission a real alternative to current high voltage ac (HVAC) transmission. When the network is decoupled from the wind farm by a dc link, there is no need for a mandatory use of three-phase generator. To the contrary, multi-phase generators can be used and the wind farm can benefit from inherent advantages and recent developments of multi-phase drives. This preliminary study shows some of the potential advantages of the dual three-phase generators in wind energy conversion systems (WECS).
\end{abstract}

Keywords: Multi-phase systems, wind energy conversion, high voltage de transmission.

\section{Introduction}

Wind energy has become an issue of significant interest achieving a spectacular increase in the last years [1]. This has been both because of technology improvements and due to ambitious European Union objectives. The European Union requirements regarding renewable energies have been recently tightened with mandatory goals, and the trend of increasing the installed wind power is going to be maintained in the next years. Among the whole expected wind energy growth, offshore is going to play a major role in new installations because of the benefits related to higher wind speeds, visual impact and land use. Offshore wind farms are nowadays planned to be installed in the open sea with distances of above $100 \mathrm{~km}$ to the transmission grid [2]. The critical distance for the use of HVDC instead of HVAC transmission has been estimated to be between 40 and $90 \mathrm{~km}$ [3], [4]. Consequently, the use of voltage source converter high voltage dc (VSC-HVDC) transmission together with offshore WECS is becoming already an alternative to conventional HVAC. In fact, VSC-HVDC has been used by $\mathrm{ABB}$ to supply an oil and gas platform $65 \mathrm{~km}$ offshore in Bergen [5]. The same company opens the possibility to use this technology for off-shore wind farms. HVDC is advantageous compared to HVAC because issues related to reactive power, harmonics and limited transmission length, do not exist anymore. The use of VSC-HVDC for offshore WECS has been already proposed following similar schemes than in onshore systems, i.e. using doubly-fed induction generators (DFIGs) and afterwards converting to dc [6]. A different approach has been proposed in [7] by using dc grid for the wind farm. Another solution is the use of full-power converters instead of DFIGs [1], although this option makes more sense for onshore applications or offshore HVAC systems. In any case, once you have a decoupling dc link and once you are using VSCs anyway, there is no need for the mandatory use of three-phase machines. This applies both to the case of full-power back-to-back VSCs and to the case of off-shore WECS with VSC-HVDC. Nevertheless, the use of multi-phase generators for wind power applications as an alternative to standard three-phase generators has hardly been considered so far [8].

Research on multi-phase machines has also followed a path of spectacular increase since the beginning of the $21 \mathrm{st}$ century, and new techniques for the control of the multiphase VSCs and machines have been successfully developed [8]. Multi-phase systems offer different advantages compared to three-phase systems, such as higher reliability [9], higher power density [10], power segmentation, lower current ripple [11] or the possibility of achieving independent control of multi-machines systems supplied from a single inverter [12]. Both multi-phase and offshore WECS are emerging technologies, and this preliminary study combines the use of multi-phase generators and offshore wind farms to jointly provide improved performance. In offshore systems it is desirable that both offshore and onshore systems provide an independent control in order to avoid communications [7], so that the turbine-side VSC only takes into account the dc link voltage level which is maintained constant by the grid-side VSC. As a consequence the control of the wind farm generators is carried out just measuring the dc link voltage. This work is focused on the wind farm side to show the resultant performance when using multi-phase generators. The control of the grid side converter, that would be in charge of transmitting the wind farm active power (maintain the dc link voltage) and the grid demanding reactive power, is described but not simulated in this paper. Among multiphase machines, the dual three-phase machine (also called asymmetrical six-phase or split-phase machine) is one of the most popular options [8] because it can be obtained from a conventional three-phase machine by splitting the phase belt and because dual conventional three-phase VSCs can also be used. The six-phase machines reduces to one half the perphase current for the same power and voltage ratings, reduces the dc link current ripple and allows post-fault operation. This study points out the mentioned advantages both in steady-state and transient operation. 


\section{WECS model description.}

A. Model summary.

A scheme of the WECS model is depicted in Fig. 1. The wind energy conversion system (WECS) consists of a pitch controlled wind turbine driving a dual three-phase induction generator (IG) and a back-to-back voltage source converter (VSC) system connected to the host AC gird network. The induction generator is connected to a vector controlled pulse width modulated (PWM) six-phase VSC, termed machineside VSC further on. The dc link is connected to the host $\mathrm{AC}$ grid network through a VSC, termed grid-side VSC further on. This model is essentially the same both for onshore fullpower WECS and for offshore WECS with VSC-HVDC. In the former case the dc link consists of a capacitor interconnecting the back-to-back two level VSCs while in the second case the dc link models the submarine cable interconnecting the offshore converter (machine-side VSC) and the onshore converter (grid-side VSC). The system depicted in Fig. 1 can also include a storage system (e.g. a capacitor bank connected at the dc bus through a full-bridge dc-dc converter [13]) to smooth the output power, but this consideration is out of the scope of this work.

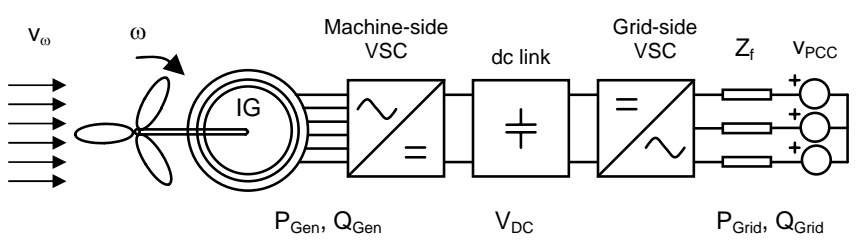

Fig. 1. Model summary of the proposed WECS.

\section{B. Variable speed pitch controlled wind turbine.}

The wind turbine receives the mechanical power from the wind according to [13]-[14]:

$$
P_{m}=\frac{1}{2} \rho_{a} A_{s} V_{w}^{3} C_{p}(\beta, \lambda)
$$

where the performance coefficient $C_{p}$ is dependent on the blade pitch angle $\beta$ and the tip speed ratio $\lambda$ :

$$
\lambda=\frac{V_{t}}{V_{w}}=\frac{R_{t} \omega}{V_{w}}
$$

The performance coefficient function is non-linear and has been approximated using [14]:

$$
C_{p}(\beta, \lambda)=0.73\left(\frac{151}{\lambda_{1}}-0.58 \beta-0.002 \beta^{2.14}-13.2\right) e^{\frac{18.4}{\lambda_{1}}}
$$

where

$$
\lambda_{1}=\left(\frac{1}{\lambda-0.02 \beta}-\frac{0.003}{\beta^{3}+1}\right)^{-1}
$$

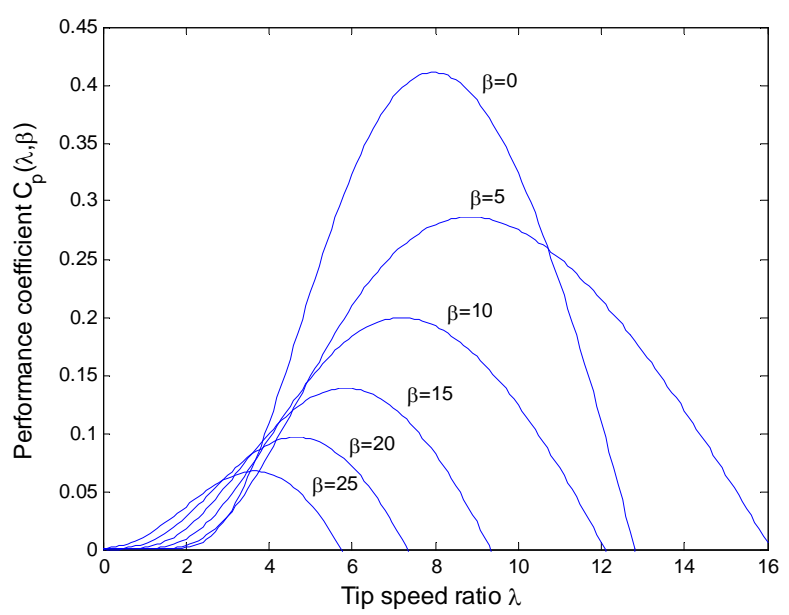

Fig. 2: Performance coefficient $C_{p}$ as a function of the blade pitch angle $\beta$ and the tip speed ratio $\lambda$.

\section{Machine-side control.}

\section{A. Dual three-phase generator and VSC models.}

The dual three-phase IG can be modelled following the double $d q$ approach or using the vector space decomposition (VSD) approach [15]. Since the latter option has proved to provide a better insight in the dynamics of the machine, it will be used further on for the modelling of the generator and VSC. The VSD approach decomposes the five-dimensional space (one degree of freedom is lost assuming isolated neutral) into two subspaces plus the zero sequence component. One subspace is termed $d-q$ (or $\alpha-\beta$ if it is expressed in the stationary reference frame) and it is responsible for the flux creation and the torque production. The other subspace or plane is termed $x-y$ [8] and it is responsible for additional losses, due to circulating stator currents in the machine, and does not contribute to the overall torque generation. The VSD converts phase abc-def values into $\alpha \beta$-xy components using the power invariant transformation matrix [15]:

$\underline{M}=\frac{1}{\sqrt{3}}\left(\begin{array}{cccccc}1 & c 4 \alpha & c 8 \alpha & c \alpha & c 5 \alpha & c 9 \alpha \\ 0 & s 4 \alpha & s 8 \alpha & s \alpha & s 5 \alpha & s 9 \alpha \\ 1 & c 8 \alpha & c 4 \alpha & c 5 \alpha & c \alpha & c 9 \alpha \\ 0 & s 8 \alpha & s 4 \alpha & s 5 \alpha & s \alpha & s 9 \alpha \\ 1 & 1 & 1 & 0 & 0 & 0 \\ 0 & 0 & 0 & 1 & 1 & 1\end{array}\right)$

where $c$ and $s$ denote cosine and sine functions respectively, being $\alpha=\pi / 6$. 
Using the transformation matrix (5) the IG equations in $\alpha \beta$-xy components can be expressed in the stationary reference frame. Because of the limited bandwidth of PI controllers, the sinusoidal $\alpha \beta$ components are projected on to a rotating $d q$ reference frame through the following rotational matrix:

$$
R=\left(\begin{array}{cc}
\cos \theta_{a} & -\sin \theta_{a} \\
\sin \theta_{a} & \cos \theta_{a}
\end{array}\right)
$$

where $\theta_{a}=\int \omega_{a} d t$ is the angle of the arbitrary reference frame rotating at an angular frequency $\omega_{\mathrm{a}}$.

The final equations in $d q-x y$ components can be expressed in state-space form as:

$$
\begin{aligned}
& p i_{d s}=c_{2}\left(v_{d s}-R_{s} i_{d s}\right)+c_{3}\left(R_{r} i_{d r}+\omega i_{q r} L_{r}+\omega i_{q s} L_{m}\right)+\omega_{a} i_{q s} \\
& p i_{q s}=c_{2}\left(v_{q s}-R_{s} i_{q s}\right)+c_{3}\left(R_{r} i_{q r}-\omega i_{d r} L_{r}-\omega i_{d s} L_{m}\right)-\omega_{a} i_{d s} \\
& p i_{d r}=c_{3}\left(R_{s} i_{d s}-v_{d s}\right)+c_{4}\left(-R_{r} i_{d r}-\omega i_{q r} L_{r}-\omega i_{q s} L_{m}\right)+\omega_{a} i_{q r} \\
& p i_{q r}=c_{3}\left(R_{s} i_{q s}-v_{q s}\right)+c_{4}\left(-R_{r} i_{q r}+\omega i_{d r} L_{r}+\omega i_{d s} L_{m}\right)-\omega_{a} i_{d r} \\
& p i_{x s}=c_{5}\left(v_{x s}-R_{s} i_{x s}\right) \\
& p i_{y s}=c_{5}\left(v_{y s}-R_{s} i_{y s}\right) \\
& p \omega=\frac{P}{J}\left[P L_{m}\left(i_{d r} i_{q s}-i_{q r} i_{d s}\right)-T_{m}-\frac{\beta}{P} \omega\right]
\end{aligned}
$$

where

$$
C_{1}=L_{s} L_{r}-L_{m}^{2} \quad C_{2}=\frac{L_{r}}{C_{1}} \quad C_{3}=\frac{L_{m}}{C_{1}} \quad C_{4}=\frac{L_{s}}{C_{1}} \quad C_{5}=\frac{1}{L_{l s}}
$$

The six-phase VSC is modelled neglecting the losses and considering ideal characteristics. The output leg and phase voltages depend solely on the individual switching functions $\mathrm{S}_{\mathrm{i}}$ of each leg [16].

\section{B. Dual three-phase generator and VSC control.}

The maximum power extracted from the wind (1) is dependent on the turbine speed $\omega$ and the wind speed $\mathrm{v}_{\omega}$ as shown in Fig. 1. The aim of the IG control is to efficiently regulate the rotor speed in order to achieve a maximum power point tracking (MPPT) that assures maximum active power delivery from the wind to the network. Each wind speed has an optimum turbine speed to obtain maximum generated power. This optimum value for the rotor speed can be approximated by [13]:

$$
\omega^{*}=\omega_{M P P T}=\sqrt[3]{\frac{P_{G e n}}{K_{p o p t}}}
$$

The reference speed $\omega^{*}$ is defined according to (9), the flux in the IG is set to the rated value (except in the field weakening region), and the wind torque is obtained from (1). The proposed speed control is an indirect field oriented control (IFOC) where the speed of the reference frame is set to $[8]$ :

$$
\omega_{a}=\omega+\omega_{\text {slip }}=\omega+\frac{i_{q s}}{T_{r} i_{d s}}
$$

The controller methodology is shown in Fig. 3. Two PI controllers are used to control the direct and quadrature currents of the IG and a further outer PI control is used for the speed control. Voltage decoupling shown in Fig. 3 for $d$ $q$ components is required for proper operation, being $\mathrm{e}_{\mathrm{d}}$ and $\mathrm{e}_{\mathrm{q}}$ the decoupling terms:

$$
e_{d}=-\omega_{a}\left(1-\frac{L_{m}^{2}}{L_{s} L_{r}}\right) L_{s} i_{q s}^{*} \quad e_{q}=\omega_{a} L_{s} i_{d s}^{*}
$$

The $x-y$ reference voltages and currents are set null and no controllers are used. This is valid if quasi-balanced operation is assumed [17], i.e. there are no machine or supply asymmetries. Otherwise $x-y$ controllers can be used [18]. The output of the control is transformed to phase values using (5)-(6), providing the input reference phase voltages for the pulse width modulation (PWM). This study adopts a space vector PWM based on two independent modulators for the two windings ( $a b c$ and def) with a spatial shifting of $30^{\circ}$. The SVPWM is carried out at $5 \mathrm{kHz}$ following a standard sector-based approach similar to three-phase systems.

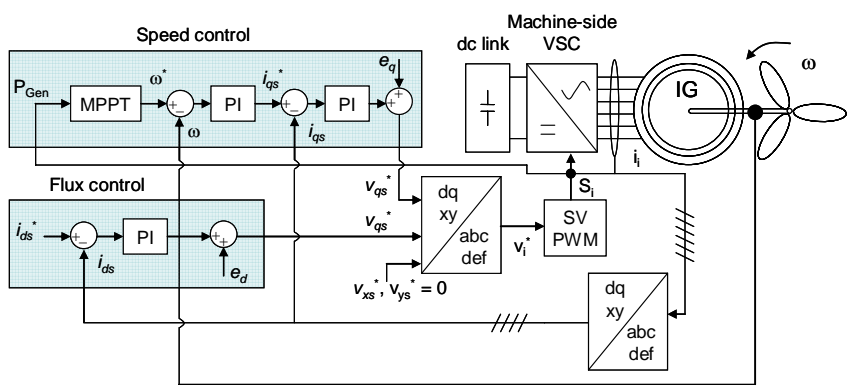

Fig. 3. Scheme of the machine-side control.

\section{Grid-side control.}

\section{A. Grid-side model.}

The ultimate control of the active and reactive power injected to the network is carried out by the vector-controlled grid-side VSC as shown in Fig. 4. In order to define the gridside control, it is firstly necessary to define the equations of the grid-side equivalent circuit. Since the control structure is highly simplified if one deals with DC instead of AC magnitudes, the equations are considered in a synchronous reference frame aligned with the grid voltage vector $\mathrm{V}_{\mathrm{PCC}}$ at the point of common coupling (PCC), yielding [6], [7], [13]:

$$
\begin{aligned}
& v_{V S C d}=R_{f} i_{g d}+L_{f} \frac{d i_{g d}}{d t}-\omega_{e} L_{f} i_{g q}+v_{P C C d} \\
& v_{V S C q}=R_{f} i_{g q}+L_{f} \frac{d i_{g q}}{d t}+\omega_{e} L_{f} i_{g d}
\end{aligned}
$$


where $v_{V S C d}$ and $v_{V S C q}$ are the $d$ - $q$ voltages at the output of the grid-side VSC, $i_{g d}$ and $i_{g q}$ are the grid $d$-q currents, $\mathrm{V}_{\mathrm{PCCd}}$ is the direct component of the voltage at the PCC, $\omega_{\mathrm{e}}$ is the electrical grid angular frequency and $R_{f}$ and $L_{f}$ are the equivalent resistance and inductance between the grid-side VSC and the PCC (including the transformer leakage inductance and modelling the converter losses).

The orientation of the equations in (12) along with the PCC voltage allows a decoupled control of the active and reactive power injected to the $\mathrm{AC}$ network by controlling the grid direct and quadrature components respectively [7], [13]:

$P_{\text {grid }}=\frac{3}{2} v_{P C C d} i_{g d}$

$Q_{\text {grid }}=\frac{3}{2} v_{P C C d} i_{g q}$

\section{B. Grid side control.}

The aim of the grid-side control is to maintain the dc bus and PCC voltages at certain reference values. The dc bus voltage depends solely on the active power, which in turn is a function of the direct grid current. Similarly, the PCC voltage depends on the reactive power and ultimately on the quadrature grid current (12). The control structure for both the $\mathrm{dc}$ bus and PCC voltages is designed with an inner current controller and a cascade outer voltage controller (Fig. 4).

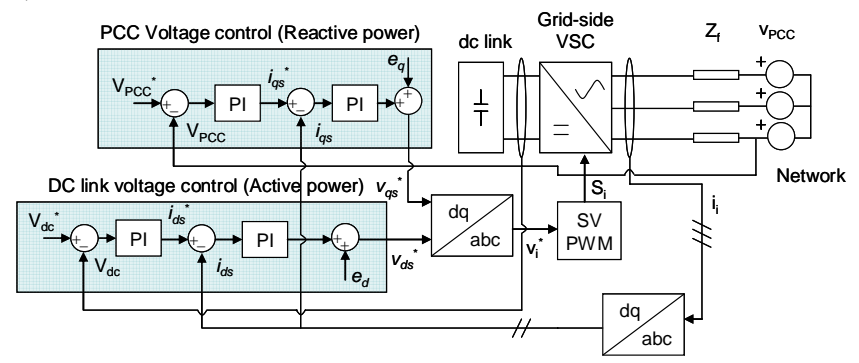

Fig. 4. Scheme of the grid-side control.

Additional terms from (12) are included at the output of the current controllers for dynamic decoupling compensation, similarly to the adopted procedure in the machine-side control:

$$
e_{d}=-\omega_{a} L_{s} i_{q s}^{*} \quad e_{q}=\omega_{a} L_{s} i_{d s}^{*}
$$

This control structure assures a stiff operating dc bus voltage [4] and allows the transference of the generated power from the machine side to the grid side. It must be noted that in the transient state the reference for the active power can be imposed by the grid requirements assuming variable dc bus voltage [19]. Furthermore, the reference for the reactive power can be imposed from a global voltage controller, instead of the local voltage control depicted in Fig. 4. However, both considerations are out of the scope of this paper and standard operation is assumed from now.

\section{Simulation results.}

\section{A. Steady state performance.}

The steady state performance has been tested assuming a constant wind speed which in turn leads to a constant wind torque. The VSCs are operated at $5 \mathrm{kHz}$ and the IG is magnetized with rated direct current. The IG parameters and rated values are scaled according to lab rig requirements and the drive performance is verified with standard conditions. The machine-side VSC voltage is depicted in Fig. 5 showing the waveform and spectrum. The waveform shows the standard PWM-based performance and the dual three-phase space vector PWM technique shows satisfactory results. The phase currents are shown in Fig. 6 in steady state showing the phase displacement of $30^{\circ}$ between the two sets of threephase windings. The steady state performance is improved compared with the standard three-phase case because the perphase currents are halved and the spectrum shows a lower harmonic content.
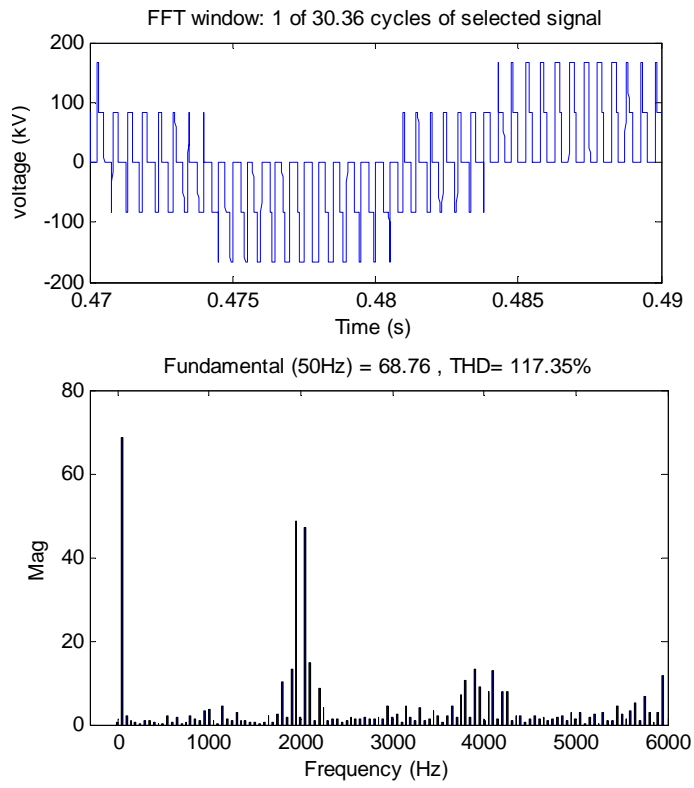

Fig. 5: Phase voltage in steady state.

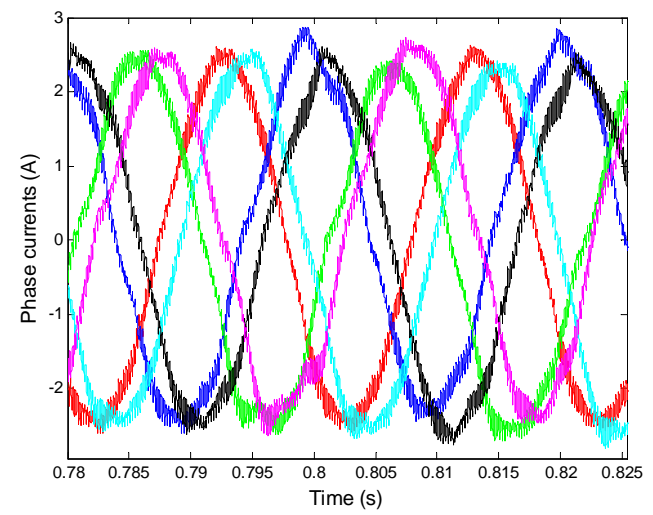

Fig.6: Phase current in steady state. 


\subsection{Transient performance.}

The transient performance has been tested considering a worst case scenario: a start-up and shut-down of all turbines in the wind farm [7]. These two cases illustrate how the dynamics of the multi-phase generator are similar to their three-phase counterpart. The target (optimum) speed and the rotor speed are shown in Fig. 7 showing a good speed tracking and an adequate behaviour in the low speed region. The quadrature current is depicted in Fig. 8 showing the transient behaviour during the braking and acceleration stages. The controllers act adequately leading to a proper speed tracking as shown in Fig. 7. The phase voltage of phase ' $\mathrm{d}$ ' is shown in Fig. 9 in the acceleration transient. It can be noted how the voltage is held constant in the mean value while the reference speed is null. The voltage frequency starts to increase as the machine accelerates. The phase currents are finally shown in Fig. 10 showing a proper performance in the transient state. The transition from rated speed to zero speed and viceversa is properly performed imposing currents of Fig. 10. An improved transient performance can be achieved by using a different number of phases (e.g. five) and considering a concentrated-winding machine with higher order spatial harmonics [8]. However, this possibility is restricted in dual three-phase machine to the case when the neutral is connected to the mid-point of the dc-link.

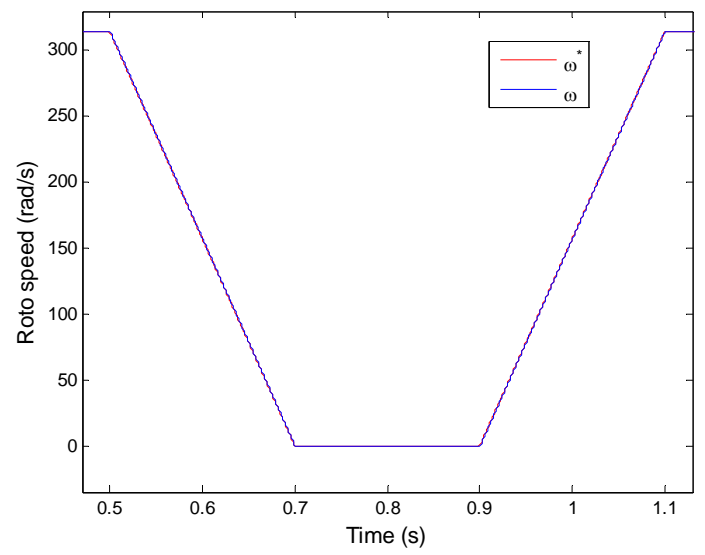

Fig. 7: Rotor speed during wind farm stop and start-up.

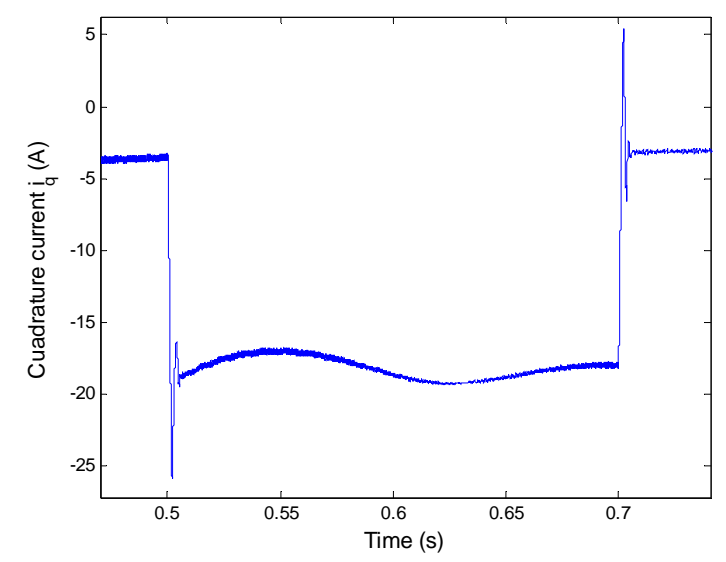

Fig. 8: Quadrature current in transient state.

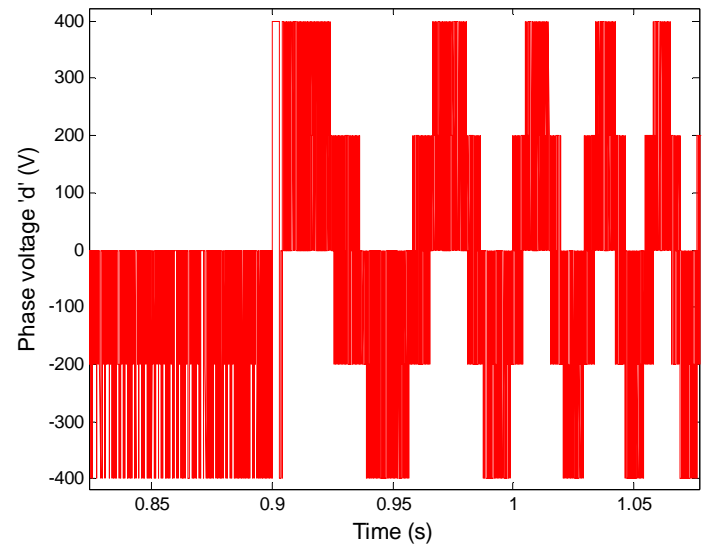

Fig. 9: Phase voltage 'd' in transient state.

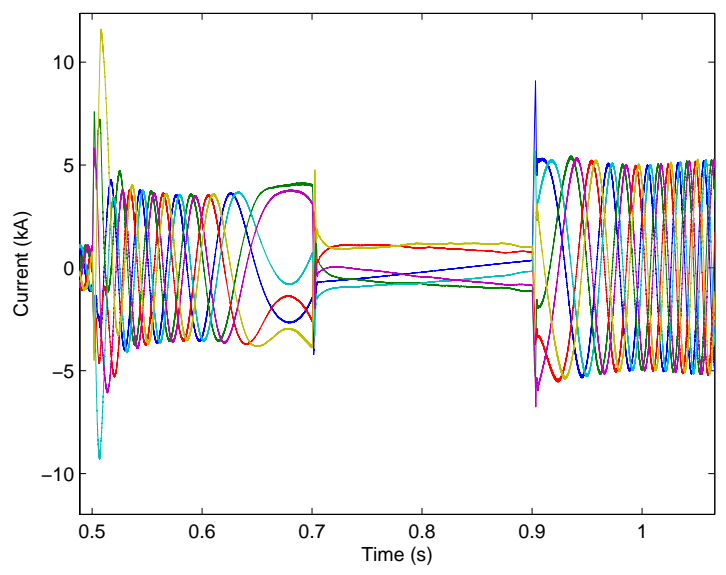

Fig. 10: Phase currents during wind farm stop and start-up.

\section{Conclusions.}

The advantages and new developments for multiphase machines can be transferred from applications such as traction, aerospace or ship propulsion to the case of offshore wind farms if full-scale power converters are used or if VSCHVDC transmission is used. The use of dual three-phase machines in such cases increases the reliability of the wind farm due to the possibility of achieving post-fault disturbance free operation. In addition, the inherent power splitting and the harmonic reduction due to the increased number of phases improve the performance of the wind farm. The results shown in the paper demonstrate that the transient performance is maintained similar to the standard three-phase case although it could be improved through torque enhancement if a different number of phases rather than six is considered. The complexity of the control structure is essentially the same compared to three-phase drives and the complexity of the space vector PWM technique is also low if no overmodulation is required. The above mentioned advantages can compensate for the additional installation costs in offshore applications where reliability is a main concern. 


\section{References.}

[1] Ullah, N.R., Thiringer, T., "Variable Speed Wind Turbines for Power System Stability Enhancement", IEEE Trans. on Energy Conversion, vol. 22, no. 1, 2007, pp. 52-60.

[2] Kirby, N.M., Xu, L., Lucket, M., Siepmann, W., "HVDC transmission for large offshore wind farms", Power Engineering Journal, Germany, 2002.

[3] Bahrman, M.P., Johnson, B.K., "The ABCs of HVDC transmission technologies", IEEE Power and Energy Magazine, 2007, pp. 32-44.

[4] Bresesti, P., Kling, W.L., Hendriks, R.L., Vailati, R., "HVDC connection of offshore wind farms to the transmission system”, IEEE Trans. on Energy Conversion, vol. 22, no. 1, 2007, pp. 37-43.

[5] Stendius, L., Jones, P., "The challenges of offshore power system construction - bringing power successfully to troll A, one of the worlds largest oil and gas platforms", ABB 2006, pp. $75-78$.

[6] Bozhko, S.V., Blasco-Giménez, R., Li, R., Clare, J.C., Asher, G.M., "Control of offshore DFIG-based wind farm grid with line-commutated HVDC connection", IEEE Trans. on Energy Conversion, vol. 22, no. 1, 2007, pp. 71-78.

[7] Meyer, C., Hoing, M., Peterson, A., De Doncker, R.W., "Control an design of DC-grids for offshore wind farms", IEEE conference, 2006, pp. 1148-1154.

[8] Levi, E., Bojoi, R., Profumo, F., Toliyat, H.A., Williamson, S., "Multiphase induction motor drives - a technology status review", IEE Elec. Power appl., vol. 1, no. 4, 2007, p. 489516.

[9] L. Parsa, H.A. Toliyat, "Fault-tolerant five-phase permanent magnet motor drives", in Proceedings of the IEEE Ind. Appl. Soc. Annual Meeting IAS, Seattle, USA, 2004, pp. 1048-1054.

[10] Xu, H., Toliyat, H.A., and Petersen, L.J., 'Five-phase induction motor drives with DSP-based control system', IEEE Trans. on Power Electronics, vol. 17, no. 2, pp. 524-533, 2002.
[11] Williamson, S., and Smith, A.C., "Pulsating torque and losses in multiphase induction machines", IEEE Trans. on Industry Applications, vol. 39, no. 4, pp. 986-993, 2003.

[12] E. Levi, M. Jones, S. Vukosavic and H.A. Toliyat, "A novel concept of a multiphase, multi-motor vector controlled drive system supplied from a single voltage source inverter," IEEE Trans. on Power Electronics, vol. 19, no. 2, 2004, pp. 320335.

[13] Strachan, N.P.W., Jovcic D., "Dynamic modelling, simulation and analysis of an offshore variable-speed directly-driven permanent-magnet wind energy conversion and storage system (WECSS)", 2007.

[14] Heier, S., "Grid Integration of wind energy conversion systems", Chichester, Wiley, 1998.

[15] Y. Zhao, T.A. Lipo, "Space vector PWM control of dual three-phase induction machine using vector space decomposition," IEEE Trans. on Industry Applications, vol. 31, no. 5, pp. 1100-1109, 1995.

[16] Duran, M.J., Toral, S., Barrero, F., Levi, E.: 'Real-Time Implementation of Multi-Dimensional Five-Phase Space Vector Pulse Width Modulation', IET Electronics Letters, 2007, 43, (17), pp. 949-950.

[17] Bojoi, R., Tenconi, A., Griva, G., Profumo, F.: 'Vector control of a dual-three-phase induction-motor drive using two current sensors', IEEE Transactions on Industry Applications, 2006, 42, (5), pp. 1284-1292.

[18] Bojoi, R., Levi, E., Farina, F., Tenconi, A., Profumo, F.: 'Dual three-phase induction motor drive with digital current control in the stationary reference frame', IEE Proc. Electr. Power Appl., 2006, 153, (1), PP. 129-139.

[19] Mauricio, J.M, León, A.E., Gómez-Expósito, A., Solsona, J.A., "An adaptive nonlinear controller for DFIM-based wind energy conversión systems", IEEE Trans. on Energy Conversion, (in press). 